\title{
Mõningaid võrdlusmomente Kesk-Assüüria ja Uus-Assuiüria raidkirjadest, kroonikatest ja annaalidest 1500-612 eKr ning nende tekstide tõlkimisega seotud probleemid
}

\section{Vladimir Sazonov}

Teesid: Käesolev artikkel vaatleb Assüüria kuningate ametlikke tekste - raidkirju, annaale ja kroonikaid valikuliste ametlike tekstide näidete põhjal, mis pärinevad eri ajastutest, jälgides, kuidas arenes Assüürias "ajaloo" kirjutamine ehk kuidas arenes välja kroonikate, annaalide ja raidkirjade koostamine läbi II ja I eelkristliku aastatuhande. I eelkristliku aastatuhande alguseks leiab aset sellise žanri väljakujunemine nagu "annaalid”. Annalistika areneb eriti Uus-Assüüria impeeriumi ajastul. Samuti näidatakse artiklis ametliku propaganda arengut Assüürias, sest kõik ülalmainitud tekstiliigid olid propagandistliku sisuga - eesmärgiga kiita valitsevaid kuningaid ning ülistada nende tegusid, legitimeerida nende võimu ning tugevdada positsioone. Tähelepanu pööratakse ka mõningatele tähtsamatele küsimustele ja probleemidele, mis on seotud niisuguste tekstide tõlkimisega.

Märksõnad: Assüüria, kroonikad, raidkirjad, annaalid, ideoloogia, kuningas, propaganda, tõlkeprobleemid. 


\section{Sissejuhatus ja ajalooline taust ${ }^{7}$}

Käesolevas artiklis vaatleme vaid valikuliselt mõningaid näiteid Kesk-Assüüria (u 1500-1000 eKr) ja Uus-Assüüria (u 900-612 eKr) kuningate kroonikatest, raidkirjadest ja annaalidest. Suurem osa näiteid on pärit Uus-Assüüria ajastust ehk siis perioodist, mida dateeritakse alates Aššurnasirpal II (883-858) valitsemisest kuni Uus-Assüüria impeeriumi hävinguni, mis leidis aset 612. a eKr (Assüüria ajaloo kohta vt lähemalt Artzi 1978: 25-41; CancikKirschbaum 2003; Faist 2001; Harrak 1987; Heinhold-Krahmer 1988: 79-104; Holloway 2002; Lambert 1974: 103-109; Llop Raduá 2001; Mayer 1995; Oded 1979; Olmstead 1917: 169-185; Brinkman 1997: 1-16.). Samas on toodud näited ka Vana-Assüüria perioodist (2000-1500 eKr), et paremini demonstreerida kroonikate ja raidkirjade kirjutamise arengut ja mõista, kuidas tekkis ning arenes Assüürias "ajaloo kirjutamine".

Artikli sissejuhatavas osas anname põgusa ülevaate Assüüria ajaloost alates Aššuri linnriigi tekkest ning analüüsime ka varasemate perioodide kuninglikke tekste, eelkõige raidkirju, aga ka kroonikaid. Siinkohal tuleb märkida, et arvestama peab tohutu kirjaliku pärandiga, mis meieni on jõudnud uus-assüüria kroonikate ja annaalidena (vt nt Grayson 1975; Grayson 1976; ITN; Glassner 2004; Stein 2000; Grayson 2002; RIMA 3; Rasmussen 1897; Wiseman 1958; Parpola, Watanabe 1988; Tadmor 1994;RINAP 4). Teatud perioodide tekstide korpused võivad olla väga mahukad ning seetõttu on käesoleva artikli autor keskendunud vaid valikuliselt mõningatele näidetele, mis kõige paremini võiksid illustreerida neid akkadi keele assüüria dialektis kirja pandud annaali- ja kroonikalaadseid tekste, mis on täiesti omaette žanr akkadikeelses kirjanduses. Assüüria kroonikaid, annale ja raidkirju on uuritud

7 Käesolev artikkel valmis Eesti Teadusfondi grantide 8669 ja 8993 toetusel. Muistse Mesopotaamia varasemate perioodide jaoks kasutatakse pikka, keskmist ning lühikest kronoloogiat. Artikli autor eelistab kasutada keskmist kronoloogiat. 
ja analüüsitud ka varem (Borger 1961; Liverani 1992; Röllig 1967: 173-184; Yamada 2000).

Esmalt aga mõni sõna Assüüria riigi kujunemisest. Võimas Uus-Assüüria impeerium sai 9-7 saj eKr alguse väikesest PõhjaMesopotaamia linnriigikesest nimega Aššur, mis oli alguses sõltuv muistsetest Mesopotaamia suurriikidest ja ei mänginud mingit rolli kuni II eelkristliku aastatuhande teise pooleni. Kuid muistsed Mesopotaamia administratsiooni etableerumise traditsioonid ja võimustruktuurid olid assüürlastele tuttavad juba vähemalt Akkadi (2354-2154) ja Uus-Sumeri (2112-2004) ajastust, mil Aššur oli väike provintsilinn võimsa Akkadi impeeriumi ja hiljem Uus-Sumeri suurriigi koosseisus. Aššur ise, hilisem tulevase tugeva Assüüria impeeriumi poliitiline keskus ja tuumik, oli II eelkristliku aastatuhande alguses veel väike ja poliitiliselt üpris nõrk, kuid samas rikas linnriik. Selle majandusliku tugevuse baas oli loodud 20-19 saj eKr. Aššuri linna kaupmehed koloniseerisid edukalt Väike-Aasia idapoolseid alasid. Niisiis sai Aššuri linn rikkaks oma linna kaupmeeste tõttu, kuna nad rajasid üpris aktiivselt oma kaubanduslikke keskusi ja kolooniad Anatoolia aladele. Tuntuim selline muistne keskus oli karum Kaneš ${ }^{8}$ (Jankovskaja 1968; Veenhof 1972).

19. saj lõpus sattus Põhja-Mesopotaamia, sealhulgas Aššuri linnriik amoriidi päritolu kuninga Šamši-Adad I (1813-1781) ülemvõimu alla, kes lõi Põhja-Mesopotaamia ja Süüria aladele võimsa suurriigi. Kuid pärast Šamši-Adad I surma, mis leidis aset ca 1781. eKr, käis Šamši-Adadi suurriik alla.

Oma valitsemise ajal tugev ja militaristlike kalduvustega ŠamšiAdad I kontrollis tervet Põhja-Mesopotaamia piirkonda kuni Eufrati jõeni välja. Ta määras oma poegi ja sugulasi vallutatud aladele asehalduriteks ja valitsejateks. Näiteks üks tema poegadest Išme-Dagan sai niimoodi Ekallatumi linna valitsejaks ning ta

8 karum Kaneš - türgipäraselt Kültepe - Türgi aladel asuv muistne ruuniküngas Kaneš oli rajatud juba vähemalt III at eKr. II aastatuhande alguses eKr lõid Aššuri kaupmehed seal oma kaubandusliku koloonia, mis puhkes õitsele ja sai teiste kolooniate peamiseks keskuseks. Sellise kaubandusliku keskuse nimetus akkadi keeles oli karum. Vt. Mayer 1995: 145. 
võimu alla olid koondatud kõik suurriigi ida-alad, tema teise poja Jasmah-Adadi residents paiknes aga Süüria aladel asuvas Mari linnas ning talle kuulusid Eufrati jõge ümbritsevad maad. Oma pealinnaks valis Šamši-Adad Sehna linna, nimetades selle ümber Šubat-Enliliks (“Jumal Enlili residents”). Šamši-Adadi surmaga varises kokku ka tema loodud impeerium. ${ }^{9}$

18. saj keskel eKr sattus Aššur järgmise suurvallutaja - Babüloni kuningas Hammurapi (1792-1750) suurriigi koosseisu, kuid juba Hammurapi poja Samsuiluna (1749-1712) ajal kaotasid Vana-Babüloonia kuningriigi (1894-1595) kuningad kontrolli Põhja-Mesopotaamia üle, kuhu tungisid sisse mägirahvad - kassiidid. 15. saj eKr muutus Aššur sõltuvaks hurriitidest, kes lõid tugeva Mitanni suurriigi Süüria ja Põhja-Mesopotaamia aladel (Solovjova, Nemirovski 2007: 140).

Ligikaudu 1595. eKr langes Babüloonia suurriik, kui selle vallutasid hetiidid. Pärast seda hakkasid Babüloonias valitsema hetiitide liitlased kassiidid. Kassiidid olid tundmatut päritolu, mägedes elavad hõimud, kes ilmusid kusagilt Iraani aladelt. Sel ajal eksisteeris Süürias ja Põhja-Mesopotaamias terve rida linnriike ja üks neist paljudest linnriikidest oli Aššuri linnriik. Aššur oli tollal poliitiliselt sõltuv kas huriitidest või kassiitidest. Aššuri valitsejad tegid ilmselt katseid lõplikult iseseisvuda ja saavutada suuremat mõjuvõimu. 14. saj II poolel eKr olukord aga muutus. Aššuri linna valitseja Aššuruballit I (1365-1330) sai esimeseks Assüüria kuningaks, kes kandis ka ametlikult "kuninga" tiitlit. Ta oli üpris edukas nii sise- kui välispoliitikas. Olles auahne ja soovides teha Aššurist suurriiki, hakkas Aššuruballit I suhtlema Egiptuse suurkuninga ehk vaaraoga nagu võrdne võrdsega ning hakkas nimetama vaaraod vennaks, mis tähendas seda, et ta pretendeeris suurkuninga staatusele ja tahtis olla võrdväärne teiste suurkuningatega - Egiptuse, Babüloonia ja Hetiidi kuningatega. Nii saigi temast varsti peaaegu terve Põhja-Mesopotaamia valitseja. Nagu mainitud, nimetas

9 Cancik-Kirschbaum 2003: 37-38. 
Aššuruballit I ennast nüüd juba kuningaks (̌̌arru). Ametlikes raidkirjades ei riskinud ta seda veel teha, kuid kirjavahetuses küll. ${ }^{10}$

Tema järglased Aššuri troonil jätkasid ta ekspansioonipoliitikat - näiteks kuningas Adadnārārī I (1307-1275) oli edukas vallutaja, kes pidas vallutussõdu nii lõunas kui ka põhjas. Tema poeg Salmanassar I (1274-1245) sõdis Mitanni kuningriigiga (Hanigalbat ehk hurriitide kuningriik), aga tal oli sõjalisi kokkupõrkeid ka Anatoolias elavate hetiitidega, samuti uruatri hõimudega (tulevane Urartu) jne. ${ }^{11}$ Järgmine kuningas Tukultī-Ninurta I ${ }^{12}$ (1244-1208) paistis silma veelgi suurema vallutajana. Vägivaldne despoot Tukultī-Ninurta I tugevdas juba niigi võimsat Assüüriat, laiendades impeeriumi piire teiste riikide arvelt. Oma võimsuse tippajal suutis Tukulti-Ninurta I kontrollida peaaegu tervet Mesopotaamiat, "neelates alla" nii Põhja-Mesopotaamia kui ka Lõuna-Mesopotaamia alad. Babüloonias valitsenud kassiitide kuningas Kaštiliaš oli sõjas purustatud ja sattus vangi (Mayer 1995: 214-215). Kassiitide suurriigi pealinn Babülon oli vallutatud ja laastatud, assüürlased olid jumal Marduki kuju Babülonist minema viinud (Weidner 1939-1941: 119). Kuid Tukultī-Ninurta I lähedastele ja õukondlastele ei meeldinud tema karm valitsemisviis. Tekkis vandenõu, mille tulemusena kuningas kuulutati hullumeelseks, kõrvaldati troonilt, vangistati ning seejärel mõrvati 1208 . või 1207. a paiku eKr. ${ }^{13}$

Kõik Tukultī-Ninurta I tehtud vallutused läksid kaotsi. Tegelikult ei läinud tal juba oma võimu lõpuaastatel enam nii hästi ja ta kaotas kontrolli Babüloonia üle, pärast ta surma käis Assüüria kiiresti alla (Sazonov 2010a: 148-150). II eelkristliku aastatuhande lõpus elas Assüüria üle veel ühe väga lühikese tõusu, mis oli seo-

10 Vt. näiteks Artzi 1978: 27, kiri nr 15, rida 3; vt Aššuruballit I kohta Sazonov 2010a: 69-76.

11 Salmanassar I vallutustest ja Assüüria administratsiooni loomisest Hanigalbatis (hurritide riik) vt Harrak 1987: 132-205; Vt ka Mayer 1995: 203205; Vt ka RIMA I, A.0.77.1, lk 183-185.

12 Tukultī-Ninurta I kohta vt Weidner 1939-1941:109-124; Klengel 1961: 67-77; Lambert 1976: 85-94; Lambert 2004, 197202.

13 Tukultī-Ninūrta I surma kohta vt Sazonov 2010a: 148-149; Sazonov 2011: 235-276; Yamada 1998: 26-27. 
tud Tiglatpileser I (1115-1077) nimega. ${ }^{14}$ Kuid tõeline Assüüria tõus algas alles I eelkristlikul aastatuhandel eKr, mil temast kasvas välja võimas kontinentaalne Uus-Assüüria impeerium. UusAssüüria impeerium sai I eelkristliku aastatuhande esimesel poolel Lähis-Idas vaieldamatult kõige võimsamaks poliitiliseks, sõjaliseks ja majanduslikuks jõuks. Assüürlased domineerisid Lähis-Idas ca 200 aastat, alates Kesk-Türgi aladest ja Kaukaasiast kuni Egiptuseni välja (Egiptuse vallutasid nad siiski vaid lühikeseks ajaks), Palestiinast Lääne-Iraanini ning Araabia poolsaareni. Uus-Assüüria impeerium oli esimene kontinentaalne impeerium maailma ajaloos, tohutult suur, multietniline, kus elas kümneid miljoneid inimesi, hästi toimiva administratsiooniga, võimsa ja mobiilse armeega ning karmi valitsemisviisiga, kus kasutati ohtralt repressiivseid meetmeid, s.h. küüditamist. ${ }^{15}$ Impeerium oli loodud vägisi - mõõga ning hirmuga. Selleks, et ära hoida selle lagunemist ja suruda maha mässulist meelt ning separatismi, kasutati luuramist, koputamist, küüditamist ja terrorit. Samal ajal muidugi arenes ja õitses Uus-Assüüria riigis kaubandus ja majandus, soositi ning toetati ustavaid vasallriike ja lojaalseid provintse ning nende elanikkonda ja ülikuid.

Uus-Assüüria kuningriik muutus 9. saj jooksul Aššurnasirpal II (883-859) ja tema poja Salmanassar III (859-824) ajal võimsaks impeeriumiks ning Assüüriast sai 9. saj teiseks pooleks praktiliselt ainus domineeriv ja tähtsam suurjõud, mis mõjutas järgmised ligi 250 aastat kogu Lähis-Ida välis- ning sisepoliitilist elu. Juba 9. saj eKr arenes assüürlaste võimas agressiivne vallutuspoliitika neljas suunas: lõunasse, põhja, itta ning läände. Vallutused ja sõjad jätkusid ka 8. ja 7. saj Uus-Assüüria impeeriumi lõplik häving leidis aset ajavahemikul 630-612 a eKr (vt. näiteks Sazonov 2006: 83; Mayer 1995: 412-418).

Niisiis tegid suur edu välispoliitilisel areenil, sõjalised võidud, keskvõimu tugevnemine jne Aššuri linnriigist 14.-13. sajandi jooksul võimsa Assüüria impeeriumi, mille jõudu ja prestiiži tunnusta-

14 Tiglatpileser I kohta Olmstead 1917: 169185.

15 Küüditamise kohta Assüürias vt Oded 1979; Sazonov 2010b: 153-174. 
sid ka teised Idamaade suurriigid nagu Egiptus, Hetiidi impeerium (1460-1180 eKr) ja Babüloonia kuningriik. Oma uudse sõjapoliitikaga, militaarsete sammudega ja võimu konsolideerimisega viis Assüüria administratsiooni tippladvik oma riigis sisse ka uuendused kuningavõimu ideoloogias, valitsemisviisis, valitsemiskontseptsioonides, administratiivses süsteemis jne. Kuid assüürlased polnud mitte ainult homo novus'e tüüpi leiutajad, vaid ka transformaatorid ja laenajad, kes laenasid teistelt rahvastelt ja riikidelt, kuid kohandasid ning transformeerisid ülevõetud nähtusi ja ideid, tehes neid endale mugavamateks ja vastuvõetavamateks (Sazonov 2010a: 237).

Assüüria võimsuse kasvuga muutus ka ametlik riiklik propaganda, arenes retoorika ja tekkis ajalookirjutus. Hetiitidelt õppisid assüürlased kirjutama annaale (vt del Monte 1993). Kroonikate koostamine oli neil juba ammu tuntud ja selle olid nad õppinud Mesopotaamiast - Babülooniast jne. Järgnevalt vaatleme Assüüria kuningate raidkirjade, annaalide ja kroonikate arengut. Kuid enne seda tuleks rääkida ka raskustest ja probleemidest, mis on seotud selliste tekstide tõlkimisega algallikatest.

\section{Mõningad olulisemad võtmeprobleemid seoses Assüüria kroonikate ja raidkirjade tõlkimisega}

Assüürlased nagu ka teised muistsed Mesopotaamia rahvad kasutasid kiilkirja, mille kunagi leiutasid sumerlased. Asssüürlased kasutasid akkadi keele assüüria dialekti, mis omakorda alates II aastatuhande algusest kuni I aastatuhande alguseni tegi läbi mitu arengufaasi - vana-akkadi keele üleminek vana-assüüria keeleks ca 2000 a eKr, seejärel kesk-assüüria dialekti teke ja areng 15.-11. saj eKr ja uus-assüüria dialekti areng 9.-7. saj, mil akkadi keel oli juba tugevasti mõjutatud aramea keele poolt - teisisõnu arameiseeritud. Muidugi olid igas dialektis omakorda aladialektid ja akkadi keel, mida kasutasid assüürlased Dur-Katlimmus 13. saj eKr, erines 
kohati drastiliselt sellest, mida kasutasid assüürlased näiteks 9. saj Ninives.

Nimetagem mõned olulisemad töö etapid, milles esile tulevate probleemidega puutub kokku selliste tekstide tõlkija:

1) kiilkirjatahvlite dešifreerimine;

2) kiilkirjamärkide translitereerimine;

3) tõlkimine;

4) mõistete tõlgendamine.

Dešifreerimine võib olla mõnikord väga tülikas ja keeruline ülesanne, eriti siis, kui tekst on halvasti säilinud või mingid laused või sõnad on kaheti mõistetavad või mõnel kiilkirjamärgil on mitu tähendust ja on raske otsustada, milline on selles kontekstis õige, sest valides vale märgi või sõna, võib muutuda kogu teksti sisu.

Lisaks raskendab tõlkimist ka asjaolu, et mõned tekstid on säilinud osaliselt, näiteks mingid kiilkirjamärgid on kadunud või isegi terved read on hävinenud. Tihti tuleb rekonstrueerida konteksti järgi, mõnikord pole see aga võimalik. Siinkohal toon ühe näite kesk-assüüria ajastust, mis seda probleemi hästi illustreerib.

On olemas kiri (pärit Ugaritist) $R \check{S} 34.165$ - see on Assüüria kuninga kiri, mis on saadetud Ugariti valitsejale, kes oli 14-13 saj eKr Hetiidi suurkuningate vasall. Kirjas on juttu sellest, kuidas "vennalikud" suhted Assüüria ja hetiitide vahel katkesid, kuna nende vahel puhkes sõda Nihria ${ }^{16}$ linna pärast (Nemirovski 2008: 5-7). Nihria all toimunud lahingus sai Hetiidi kuningas Tuthalija IV assüürlaste käest lüüa. Vähemalt nii väidab Assüüria kuningas, kes isiklikult selle kirja koostas. Kuid kes see Assüüria kuningas võis olla? Kas Salmanassar I või Tukultī-Ninurta I? Saatja nimest on säilinud vaid märgid ... SAG LUGAL KUR... - “... SAG, Assüüriamaa kuningas..." (Nemirovski 2008: 6).

Üks tõlgendamisvõimalus on, et SAG ette käis märk UR, mis kokku annab UR.SAĞ ehk 'kangelane' (akkadi keeles hääldati seda qarrādu $(m))$.

Teine variant on see, et märk SAG võib kuuluda Salmanassari nimesse (originaalis kirjutati ta nimi šùl-ma-nu-SAGja sedaloe-

16 Võib olla tänapäeva Diyarbakir'i kandis. 
takse akkadi keeles Šulmanu-ašared) - see tundub loogilisema ja tõenäolisema teooriana (Nemirovski 2008: 6). Seda toetab ka asjaolu, et uurides kuningate Salmanassar I ja Tukultī-Ninurta I titulatuuri nende raidkirjades, ei leidnud ma, et epiteeti UR.SAG ehk qarrādu(m) 'kangelane'oleks kasutatud enne tiitlit šar māt Ǎšsur 'Assüüria kuningas'. Salmanassar I puhul seal, kus ta kasutas tiitlit "Assüüria kuningas”, algas ta titulatuur tavaliselt järgmiselt: Šulmanu-ašared šar kiššati šarru dannu šar māt Aššur - Salmanassar, universumi kuningas, võimas kuningas, Assü̈̈ria kuningas (RIMA 1, Shalmaneser I A.0.77.6, lk 186, read 1-3).Ka Tukulti--Ninurta I titulatuuris ei näe me midagi selletaolist (Sazonov 2010a:96-148). Kirjades kasutati epiteeti UR.SAG muidugirohkem, aga ikkagi mitte enne kuninga ametlikku tiitlit "X maa kuningas". Näitena toon Hetiidi suurkuninga Šuppiluliuma I (1380-1340) tiitli alguse ühest tekstist:

1. um-ma d ${ }^{\mathrm{U}} \mathrm{TU}$-ši ${ }^{\mathrm{m}} \mathrm{S}$ u-up-pi-lu-li-ma ${ }^{17}$

2. LUGAL GAL LUGAL KUR Ha-at-ti UR.SAG (Aboud 1994: 48, read 1-2)

1. Järgmisel viisil kõneleb Minu Päike, Šuppiluliuma,

2. suurkuningas, Hatti18maa kuningas, kangelane.

Seega peab selliste tekstide tõlkija olema kursis tegelikult tervete tekstikorpustega, et vajadusel lünki täita.

Peatume põgusalt mõistete tõlgendamisega seotud raskustel. Paljusid termineid, mis on seotud näiteks Assüüria sõjandusega, küüditamisega või taimede, maagia ja meditsiiniga, on tänapäeva keeles raske edasi anda. Peamiseks põhjuseks on see, et esiteks pole meil veel terviklikku pilti nendest muistsetest kultuuridest ja teiseks pole leitud veel kõiki allikaid, mis võiksid paljude mõistete tõlgendamisel abiks olla. Terminoloogia valdkonnast toon vaid ühe näite. Näiteks kasutati küüditatute kohta Assüürias omi termineid ja neid oli koguni mitu. Siin mainiksin ära järgmised - sumero-

17 Siin on kuninga nimi kirjutatud valesti, peaks olema kiilkirjas $\check{S} u$-up-pi-luli-u-ma.

18 Ehk Hetiidi impeerium, mis eksisteeris 15 saj-12 saj alguseni eKr. 
gramm ${ }^{19}$ lúERIM.MEŠ, akkadi keeles şābū; sumerogramm ÙKU. MEŠ, akkadi keeles nišü; sumerogramm ZI.MEŠ, akkadi keeles napšăti (Oded 1979: 22).Kõik need mõisted esinevad Assüüria kuningate annaalides ja muudest tekstides. Näiteks selline väljend nagu niše şeher rabi zikar u sinniš esineb tihti Uus-Assüüria kuningate raidkirjades (Sargon II, Sennaherib). Seda võib tõlkida kui 'inimesi, suuri ja väikeseid, meessoost ja naissoost...' (Oded 1979: 23). Nišū võis tähendada teatud kontekstis rahvast, ka niisama inimesi ja ka mehi, sõjamehi. Seega peab kindlasti oskama mõisted õigesti tõlkida ja just lähtuvalt kontekstist.

Veel üks küsimus, millele tuleks pöörata erilist tähelepanu, on see, et eri liiki tekstid nõuavad ka erisuguseid tõlkemeetodeid. Oma tõlkekogemuse põhjal võin öelda, et näiteks propagandistliku sisuga tekstid (nagu raidkirjad, kroonikad jne) sarnanevad enam ilukirjanduslike tekstidega, mille tõlkimisel tuleb edasi anda eelkõige emotsiooni ja peamist mõtet, samal ajal kui näiteks seaduste tõlkimisel tuleb eelkõige pöörata tähelepanu selgele sõnastusele ja täpsusele.

Tõlkimisel tänapäevastesse keeltesse on kindlasti veel üks tähtis probleem - lauseehitus. Kuna akkadi keele puhul on tegemist semiidi keelkonna ida-semiidi harusse kuuluva keelega, erineb selle grammatika väga näiteks eesti keele omast. Kas tõlkimisel tuleks jätta sõnajärg samasuguseks nagu on originaalis või peaks seda kohandama sihtkeele grammatikale? Tuleb vältida sõna-sõnalist otsetõlget, mis eesti keeles võib kõlada väga konarlikult ja kohati isegi arusaamatuks jääda. Seetõttu on ilukirjanduslike tekstide tõlkimise puhul peamiseks reegliks see, et tuleb kasutada nii originaalilähedast lausestruktuuri kui võimalik, aga seejuures peab sihttekst olema lugejate jaoks arusaadav ning mõelda tuleb ka sihtkeele stiili peale.

Tõlkimise seisukohast on oluline ka see, millisest perioodist konkreetne tekst pärineb. Seetôttu vaatleme järgnevalt Assüüria

19 Sumerogramm - sõna või väljend sumeri keeles, mida kasutati akkadi keeles kui laensõna või väljendit ja seda hääldati akkadi keele päraselt. Näide: sumerogramm LUGAL 'kuningas' häldati akkadi keeles kui šarru(m) ja see tähendas samuti 'kuningat'. Vt näiteks Kaplan 2006: 18. 
raidkirjade ja kroonikate arenguetappe kronoloogiliselt alates sellest ajast, mil meil on olemas esimesed valitsejate raidkirjad Aššurist.

\section{III eelkristliku aastatuhande lõpp ja II eelkristliku aastatuhande algus}

Kroonikaid ja annaale kui selliseid siis veel pole. On aga olemas esimesed Aššuri kuningate raidkirjad, mis on äärmiselt lakoonilised, struktuuri ning ülesehituse poolest lausa primitiivsed ja meenutavad vana-akkadi ning uus-sumeri raidkirju, kuid on enamasti siiski lühemad ja valitsejatel on tunduvalt tagasihoidlikum titulatuur (vt näiteks RIMA 1, A.0.35.1, lk 46; RIMA 1, A.0.60.2, lk 85).

Toon paar näidet. Esimesed teadaolevad akkadikeelsed raidkirjad Aššuri valitsejatelt pärinevad Akkadi ajastust (2334-2154), mil Aššur oli vasall-linnakesena võimsa Akkadi impeeriumi koosseisus. Esimene Aššuri valitseja või asehaldur, kellest on säilinud tekste, on Ititi. Oma raidkirja lasi ta koostada kivist tahvlile, mille arheoloogid leidsid Aššuri linna jumala Ištari pühamus. Raidkiri on äärmiselt lühike ja kõlab nii:

1-8.) i-ti-ti PA DUMU i-nin-la-ba in ša10-la-ti ga-surx(SAG).KI a-nadINANNA A.MU.RU. (RIMA 1, Ititi, A.0.1001, lk. 7, read 1-8.)

1-8.) Ititi, valitseja, Ininlaba poeg, selle (eseme) Gasuri tribuudist jumalanna Istarile pühendas

Siit algabki Aššuri raidkirjade areng, mis I eelkristliku aastatuhande esimesel poolel viis oma kompositsiooni ja stiili poolest väga keeruliste ning mahukate uus-assüüria annaalide ja kroonikate tekkimiseni. Ka Uus-Sumeri ajal 22-21 saj eKr jätkus selline tendents. Aššur oli Uus-Sumeri kuningate alluvuses kuni 2004. a eKr, mil Uus-Sumeri kuningriik hävis. 


\section{II eelkristliku aastatuhande esimene pool}

Järgmine huvitav võtmepunkt on II eelkristliku aastatuhande algus, mil Aššur sai esimest korda iseseisvaks linnriigiks. Tekkis oma kuningavõim, omad institutsioonid - enamasti muidugi mõjutatud Sumeri või Akkadi poolt. Raidkirjad on endiselt lühikesed, primitiivsed. Neid ei saa võrrelda pikkade ja põhjalikke raidkirjadega, mida koostasid Babüloonia suurkuningad, nagu näiteks Hammurapi. Aga Aššuri raidkirjades hakatakse toonitama, et valitseja on jumala asehaldur maa peal. Näiteks on nii tõlgendatud $2000 \mathrm{eKr}$ valitsenud Aššuri valitseja Şilulu raidkirja:

1-6.) $a$-šùr.KI LUGAL si-li-lu ÉNSI $a$-šùr.KI DUMU da-ki-ki NIMGIR URU a-šùr.KI.( RIMA 1, Şilulu A.0.27.1, lk 12-13, read 1-6)

Kuidas seda võiks tõlkida? Tasub kohe ära märkida, et Aššur oli assüürlaste tähtsam linn, nende riigi domeen, keskus, ja Aššur oli ka nende peajumal. Seega nii pealinn kui ka jumal kandsid ühte nime. $a$-šùr.KI LUGAL - see on huvitav koht. Akkadi keeles loeti seda kui Ǎ̌šrur šarru ehk 'jumal Aššur on kuningas', aga pärast sõna $A \check{s ̌ s} u r$ on determinatiiv ehk postnominatiiv $k i$, mis sumeri keeles tähendas mingit geograafilist piirkonda, seega Aššur.ki on hoopis linn Aššur ja sel juhul LUGAL ehk šarru on omadussõna. Raidkirja tuleks tõlkida siis järgnevalt:

1-6.) Aššuri linn on kuninglik, Silulu on Ǎšsuri linna asehaldur, Dakiki, Ařšuri linna heeroldi poeg.

Ühes huvitavas raidkirjas, mille koostas Ašsuri linna valitseja Erišum I (20. saj eKr), leiame sellise passaaži: 35.)... $a$-šù $r$ LUGAL 36.) i-ri-šu-um PA [a-šù $] r . .$. (RIMA 1, Erišum I, A.0.33.1, lk 21, read 35-36). Tõlkes on see 'Aššur on kuningas, Erišum on (tema) asehaldur'. See sarnaneb Silulu tekstiga, kuid siin on Aššur ilma determinatiivita "KI" ja tähendab seetõttu juba jumalat. See on huvitav, kuna sama väljend on 20. saj eKr kindlasti sarnane hilisema kesk-assüüria kroonimisrituaali tekstiga, mis koostati ca 13-12 saj eKr ja kus preestrid protsessiooni käigus laususid: "Aššur on 
kuningas! Aššur on kuningas!”20 Aga jätame nüüd vana-assüüria ajastu tekstid ja vaatame, mis toimus kesk-assüüria ajastul.

\section{Kesk-Assüüria raidkirjad}

Kesk-Assüüria ajastu I perioodil drastilisi muudatusi ei toimunud, seega periood 1500-1363 eKr meid siinkohal väga ei huvita. Muudatused tulid siis, kui Aššuri linnriik hakkas muutuma kuningriigiks ja sai 14. saj II poolel suureks territoriaalriigiks. See on seotud mitmete Aššuri valitsejatega, aga eelkõige Kesk-Assüüria kuninga Aššuruballit I-ga (1365-1330), keda võib vaadelda kui homo novust, sest just tema ajal leidsid Assüüria valitsemis- ja vallutamispoliitikas ning ka võimuideoloogias aset olulised muutused. Assüüria sai suurriigiks ja Aššuri valitseja saavutas 'kuninga' (̌̌arru) staatuse ning temast sai rahvusvaheliselt tunnustatud ning aktsepteeritud suurkuningas (šarru rabû). Assüüria kuningas oli nüüd igati võrdväärne teiste Lähis-Ida suurkuningatega. See tendents jätkus ning kasvas veelgi tema järeltulijate ajal. Iga uus valitseja Assüürias võttis ametlikes kuninglikes raidkirjades kasutusele uusi tiitleid ja epiteete. Tukultī-Ninūrta I valitsemisajaks kujunenud KeskAssüüria valitseja titulatuur oli väga auahne ning mitmekesine ja Kesk-Assüüria suurriik oli saavutanud oma territoriaalse maksimumi (Sazonov 2010a: 96-148; Sazonov 2011: 233-276).

Kesk-Assüüria kuningad ei kasutanud mitte ainult neid tiitleid ja epiteete, mida nad olid pärinud Aššuri valitsejatelt või võtnud üle naaberriikide valitsejatelt, vaid leiutasid ka ise mõned tiitlid ja epiteedid (selles osas paistsid eriti silma Salmanassar I ja TukultīNinurta I). Suurte vallutajate ja Kesk-Assüüria impeeriumi rajajate Adad-narari I, Salmanassar I ja Tukultī-Ninurta I raidkirjad muutusid nüüd eriti pikaks ja põhjalikuks (vt näiteks RIMA 1 A.0.78.5). Neil on pikk sissejuhatav osa nagu uus-assüüria kroonikatelgi, kus on tihti ära toodud kuninga täielik titulatuur, mis on muutunud

20 Vt lähemalt Müller 1937: 8-9, tulp I, rida 29: “Aššur šar Aššur šar2” - “Aššur ist König, Aššur ist König!”. 
üsna pikaks, kohmakaks ja auahneks; mainitud on ka genealoogiat ja kõiki tähtsamaid jumalaid, kes soosivad, toetavad või legitimeerivad valitseja suurkuninglust ja võimu. Propagandaaparaat arenes tohutult ja raidkirjades on juba põhjalikult loetletud kõik tähtsamad kuninga tiitlid, ka tema saavutused ning tekivad esimesed sõjakäikude kirjeldused. Ühest Tukultī-Ninurta I raidkirjast võib välja lugeda

Minu valitsemise alguses [ja] minu troonil olemise alguses deporteerisin ma 28800 hetiidi sõjameest sealpoolse Eufrati jõe kaldalt [Süüriast] ning tõin nad oma kuningriiki. Ma vallutasin Paphu ja Uqumanu maad kuni Šarnida ja Mehru maadeni. Igal aastal saan ma regulaarselt andamit nendest maadest ja nende mägede vilju [---]. Ma lömastasin oma jalge [ees] olevad kuningad, nende juhid, ja rakendasin nende suhtes orjust. Oma ületamatult tugeva võimsusega ületasin ma korduvalt [sageli] võimsaid mägesid [ja] ääretult raskeid vahemaid, radasid, mida ükski teine kuningas ei teagi (RIMA 1, A.0.78.23, read 27-42).

Suurte jumalate, minu isandate, jumalate Aššuri, Enlili ja Šamaši toetusel ning jumalanna Ištari abiga, taeva ja allilma emandaga, kes marsib minu armee ees, lähenesin mina Kaštiliašile, Karduniaši [Babüloonia] kuningale, et pidada lahingut [temaga]. Ma võitsin tema armee ja tapsin ta sõjamehi. Keset lahingut ma vangistasin Kaštiliaši, kassiitide kuninga [---] (RIMA 1, A.0.78.23, read 56-65).

Ajalookirjutus areneb edasi - võib leida juba üsna detailseid lahingute või sõjakäikude kirjeldusi, mis on uus-assüüria annaalidele väga omased.

Ka kuninglikus titulatuuris leiab aset murrang. Kui veel 15. saj või 14. saj alguses nimetas Aššuri valitseja ennast vaid Aššuri asehalduriks, siis 13. saj alguseks oli kõik muutunud ja kuningas Adad-nārārī I, kes tähistas end oma raidkirjades ametlikult kui šar $k i \check{s ̌ s} a t i$ - 'universumi kuningas', võttis kasutusele hulgaliselt uusi tiitleid ja epiteete, kusjuures mõned neist leiutas ta ise (Sazonov 2010a: 80-90). 
Alljärgnevalt vaid mõned näited:

1) murappiš mişri u kudurri - 'Maade ja piiride laiendaja' (Mayer 1995: 180; RIMA 1, A.0.76.1, lk. 131, rida 15: mu-ra-piš mì-iş-ri ù $k u-d u-r i)$;

2) Nēr (nāer) dapnūti ummān Kaššì Qutī Lulumī u Šubarī 'võimsate Kassiidi, Qutu, Lullumu ja Šubaru armeede võitja' (RIMA 1 A.0.76.1, lk.131, read 3-4).

Adad-nārārī I poeg Salmanassar I lisas uusi enda leiutatud tiitleid, nagu näiteks:

1) šar kiššat nišē - 'Kõikide inimeste kuningas' (RIMA 1 A.0.77.18 $1 \mathrm{k} 207$, rida 3)

2) sabit mişrat nakirī eliš u šapliš - 'Vaenulike alade vallutaja üleval ja all' (RIMA 1 A.0.77.1, lk 183, rida 18-19)

Kõnealune protsess kulmineerus Tukultī-Ninūrta I ajal, mil Kesk-Assüüria impeerium saavutas oma võimsuse tipu (Sazonov 2011: 233-276).

Niisiis iseloomustab kuninglikke raidkirju Adadnārārī I, Salmanassar I ja Tukultī-Ninurta I ajast kuningate ülistamine ja mõnikord vaenlaste halvustamine. Kuningat esitletakse vahel kui jumalikku kangelast, võitmatut, jumalate lemmikut, õiglast valitsejat.

Näitena valime vaid paar väikest fragmenti umbkaudu 60 -st Tukultī-Ninurta säilinud raidkirjast. Need ülistavad kõik viimseni Assüüria kuningat ning kirjeldavad ta vallutusi ja muid "kangelaslikke tegusid". Oma raidkirjades nimetas Tukultī-Ninurtaennast tavaliselt nii:

Tukutī-Ninūrta, universumi kuningas, võimas kuningas, Assüüria kuningas, nelja ilmakaare kuningas, kõikide inimeste päikesejumal, Salmanassari poeg ... (ITN 18, 1-3, lk. 31)

Või siis nii:

Tukulti-Ninurta, universumi kuningas, võimas kuningas, Assüüriamaa kuningas, Sumerimaa ja akkadlaste maa kuningas, nelja ilmakaare kuningas, Aššuri ja Šamaši lemmik olen ma - ülistatud võimukandja, kuningas jumal Enlili soosingul, 
kes õnnelikult oma valitsuskepiga maad rahulikult karjatab, kõrgem lunastus-preester, Anu poolt kutsutud... (ITN 16, 1-9, 26).

See pole veel kaugeltki lõplik nimekiri, kuna ainuüksi tema epiteetide nimekiri on selles raidkirjas 24 rida pikk, alles siis tuleb juttu tema vallutustest ja vägitegudest, millega võrreldes jäävad mitmedki Rooma ja Bütsantsi keisrid, Ottomani impeeriumi sultanid ja 16-18 saj Iraani valitsenud Safaviidide šahhid lihtsalt kahvatuteks isikuteks.

\section{Tukultī-Ninurta eepos ja kroonikad}

Üks huvitav kirjanduslik tekst, mis küll pole kroonika, aga on mainimisväärne, kuna käsitleb Assüüria kuninga Tukultī-Ninurta I sõdu ja tegusid, on akkadikeelne Tukultī-Ninurta eepos. ${ }^{21}$ See on huvitav propagandistlik teos, mille eesmärk oli ülistada Assüüria kuninga Tukultī-Ninurta I vägitegusid ning vallutusi. TukultīNinurta I on selles eeposes muuhulgas kujutatud Babüloonia peajumala Enlili pojana ja kangelasliku sõjaka vägilasjumala Ninurta vennana ning ka ise jumalikustatud kangelasena. ${ }^{22}$

Erilist huvi pakub rida 20', kus Tukultī-Ninurta I on mainitud Enlili pojana - úu-šar-bi-šu-ma ${ }^{d} E / I l l i l(\mathrm{BE}) k i$-ma a-bi a-li-de/i $a r-k i$ $m a \bar{r}(i)$ (DUMU) bu-uk-re/i-šu - 'Enlil kasvatas ta üles kui tõeline isa, pärast ta esmasündinud poega' (Machinist 1978: 68-69, rida 20').

See eepos oli loodud teatud eesmärkidega - asssüürlaste Babüloonia-vastase vallutuspoliitika õigustamiseks ning Assüüria valitseja isiku ülistamiseks. Benjamin R. Foster kirjutab: “TukultīNinurtat kujutatakes kui õiglast ja austusväärset kuningat, keda sundis Babülooniasse tungima ainult tema Babüloonia partneri Kaštiliaši reetlikkus, kes murdis kahe rahva vahel pikka aega

21 Vt Tukultī-Ninurta eepost B. Machinisti transliteratsioonis ja tõlkes Machinist 1978.

22 Foster 2005: 301-302, read 15'-20' 
kestnud lepingu. Tukultī-Ninurta hüüab appi tõotuste jumalat Šamaši, et see tunnistaks babüloonlaste reetlikkust, ning kutsub oma väed kokku. Hirmunud Babüloonia kuningas kahetseb oma väärtegusid ning üritab mitmesuguste riugaste abil otsest konflikti vältida. Olles viimaks sunnitud võitlusse astuma, põgeneb ta surmahirmus triumfeeriva Assüüria armee eest, mis marsib Babüloni ja rüüstab selle" (Foster 2007, 19-20). ${ }^{23}$ Kindlasti on mainimisväärt ka akkadikeelsed kroonikad, mis käsitlevad kesk-assüüria aega, näiteks "Sünkronistiline kroonika” (Glassner 2004: 176-183) või "Adrik-Dēn-Ili kroonika” (Glassner 2004: 184-187), kindlasti ka "Tukultī-Ninūrta I kroonika" (Glassner 2004: 186-187), mis kajastavad samuti assüürlaste ametlikku propagandat. See eepos oli koostatud kangelaslikus stiilis ning nagu Benjamin R. Foster õigesti märkis, "on narratiiv loodud pompöösses, heroilises stiilis" (Foster 2007: 20).

Kõik see on vaid preluudium Uus-Assüüria ajastule. Pärast Tukultī-Ninurta I surma käis Kesk-Assüüria riik alla ning Assüüria võimsus taastati alles 9. saj eKr.

\section{Uus-Assüüria ajastu (9-7 saj)}

Võib öelda, et 9-8 sajandiks eKr on välja kujunenud eraldi žanrina annaalid ja kroonikad. Need on üles ehitatud väga loogiliselt, kindla kaanoni järgi. Annaalid vaatlevad kuninga vallutusi ja tegusid ta valitsemisaastate kaupa ning üsna detailselt. Annaalide kirjutamist ja kroonikate koostamist õppisid assüürlased oma naabritelt - hetiitidelt ja babüloonlastelt. Esimesed teadaolevad annaalid

23 Tukultī-Ninurta is portrayed as a just and honorable king guided into invading Babylonia by treachery of his Babylonian counterpart, Kashtiliash who broke a long-standing treaty between the two nations. Tukulti-Ninurta calls upon Shamash, god of treaties, to witness the Babylonian's perfidy, and he assembles his forces. The Babylonian king, terrified, regrets his miseeds and seeks to avoid a direct conflict by various stratagems. Ultimately forced into an engagement, he flees for his life before the triumphant Assyrian army, which continues to Babylon itself and loots the city. 
ajaloos lõid juba Hetiidi suurkuningad II eelkristliku aastatuhande II poolel (del Monte 1993). Suurt mõju avaldas Assüüriale ka Babüloonia.

Niisiis arenes 9-7 saj lõplikult välja Uus-Assüüria ajalookirjutus. Vallutanud terve Lähis-Ida, hakkavad assüürlased "looma oma Lähis-Ida ajalugu”, kirjutades ajaloolisi sündmusi üles propagandistlikul eesmärgil. Kroonikad, annaalid ja raidkirjad on kõik mõeldud selleks, et ülistada assüürlasi ja nende valitsejat ning halvustada ja hirmutada vaenlasi. Siinkohal toome mõned näited Uus-Assüüria kuningate annaalidest ja raidkirjadest. Uus-Assüüria impeeriumi rajajaks peetakse Aššurnasirpal II (883-859) (vt lähemalt Liverani 1992). Tema annaalid on üsna huvitavad, kuid mõnes mõttes on neis näha päris palju kesk-assüüria mõjutusi ehk siis samu elemente, mida me näeme Salmanassar I, TukultīNinurta I või Tiglatpileser I raidkirjades. Käesoleva artikli piiratud mahu tõttu jääb Aššurnasirpal II raidkirjade ja annaalide vaatlemine mõnesse teise kirjutisse.

\section{Salmanassar III (858-824 eKr)}

Salmanassar III raidkirjades (nagu enamikus Uus-Assüüria kuningate raidkirjades) on peamiselt juttu küüditamisest, mõrvamisest ning andami saamisest eri piirkondadest, aga ka linnade hävitamisest ja põletamisest. See on assüüria raidkirjade või annaalide puhul üpris tavaline kirjeldus. Siinkohal mõned näited. Kui Salmanassar III liikus oma võimsa armeega Tīl-Barsipi piirkonnas üle Eufrati jõe, vallutas ta muuhulgas ka hulga väiksemaid kuningriike, alistas mitmeid hõime ja linnu, näiteks Paripa, Sūrūnu, TîlBašeri jt (Bunnes 1997: 17-28).

Ma tapsin maha palju nende [inimesi ja] viisin minema nendelt saadud saagi. Ma tegin maatasa, hävitasin [ja] põletasin ära 200 linna nende ümbruskonnas. (RIMA 3, Shalmaneser III A.0.102.2, col. II, rida 16-18, lk 18; vt ka tõlget Sazonov 2010b: 164). 
Veel ühe näitena toon Salmanassar III mõned vägivallateod, mida me loeme raidkirjas Shalmaneser III A.0.102.2. Seal on muuhulgas mainitud ka mitmete inimeste jõhkrat tapmist ning hulga kohalike vangistamist:

"Mina langetasin 700 nende sõjameest mõõgaga" (RIMA 3, Shalmaneser III A.0.102.2, col. II, lk 17, rida 3).

Samas raidkirjas hoopleb verejanuline despoot sellega, kui palju ta tappis Taia, Hazazu, Nulia ja Butāmu inimesi:

Liikudes eemale merest, vallutasin ma Taia, Hazazu, Nulia ja Butāmu linnad, mis kuuluvad patinealastele. Ma tapsin maha 2800 [nende] sõjameest [ja] viisin ära 14600 vangi (RIMA 3, Shalmaneser III A.0.102.2, col. II, lk 17, read 10-12; vt ka tõlget Sazonov 2010b: 164).

Ka kõik teised Assüüria kuningate raidkirjad on umbes samalaadsed. On muidugi mainitud ka paleede, linnade ja templite ehitamist, aga siiski on peamine rõhk sõjategevusel. Pärast Salmanassar III surma (824) käis Uus-Assüüria impeerium alla - nõrgenes ja oli kadumise äärel, kuna võimas Urartu riik ähvardas Assüüriat kogu aeg hävinguga. Kuid 8. saj teisel poolel taastas andekas väejuht Tiglatpileser III impeeriumi. Tema tekstidest alljärgnevalt juttu tulebki.

\section{Tiglatpileser III (745-728 eKr)}

Uus-Assüüria ajastu üks julmemaid valitsejaid, Assüüria võimsuse ja hiilguse taastaja oli andekas väepealik ja äärmiselt militaristlik kuningas Tiglatpileser III, kes paistis silma suure vallutaja ja reformaatorina, küüditamispoliitika ühe tähtsaima rakendajana. Tema ajal muutusidki küüditamine ja massimõrvamine assüürlaste ametlikuks riiklikuks poliitikaks. Oma raidkirjas kirjutab assüürlane, et võimsa endise suurriigi Urartu suurkuningas Sarduri olevat kuningas Tiglatpileser III enda sõnul lasknud jalga nii kiiresti kui võimalik: "Selleks, et päästa oma elu, põgenes Sarduri öösel, 
enne päikesetõusu lasi ta kiiresti jalga" (Tadmor 1994: 52, Ann. 17, tahvlid XIII-XIV, rida 10').

Selliste "vägitegudega" Tiglatpileser III muidugi ei piirdunud, vaid jätkas samas vaimus. Alljärgnevalt toome näite veel ühest kroonikast (Ann.6), mis on pärit Kalahi (Namrūdi) linnast:

1. [---] Hista, Harabisina, Barbaz’i, Tasa linna, Ulurusi jõge mööda üles, vallutasin ma ja võtsin 8650 inimest,

2. [---] 300 hobust, 600 eeslit, 1350 härga, 19000 lammast võtsin ma saagiks. Ma lammutasin, hävitasin ning põletasin tules.

3. [---] ning need linnad ma liitsin Assüüriaga. Ma ehitasin linnad taas üles ja paigutasin sinna inimesed minu poolt vallutatud maadest.

4. [---] Aššuri, mu isanda relvad seadsin üles sinna.

5. [---] Luqadanša, Quda, Elugia, Dania, Danziun'i, Ulay, Luqia, Abrania, (ja) Eusa

6. [---] ma võitsin. Ma tõin saagina kaasa 900 inimest, 150 härga, 1000 lammast, hobuseid, muulasid [ning] eesleid.

7. [---] nende linnu ma hävitasin ja laastasin ja põletasin maha. Muqania inimesed nägid tolmupilve minu [vägede] marsist, ja Uri linn [---]

(Tadmor 1994: 76, Ann. 5, lk 62, read 1-7; vt ka tõlget Sazonov 2010b: 160).

Tiglatpileser III teised annaalid on samalaadsed ning ega ka teiste Uus-Assüüria kuningate annaalid neist tegelikkuses väga erinegi. Alguses on sissejuhatus, kus mainitakse Assüüria kuningate titulatuuri ja genealoogiat ja ka tähtsamaid jumalaid nagu Aššur, Ištar, 
Šamaš jne, kes on andnud kuningluse kõnesolevale kuningale ja kes toetavad teda tema valitsemise jooksul, ükskõik millistes tegudes, olgu see sõda, ehitustööd, küüditamine vms (vt näiteks RINAP 4, Esarhaddon 57, lk 121, Col. i, read 1-13).

Tiglatpileser III raidkirju ja annaale on säilinud piisavalt palju ning neis toodud arvud on alati suured. Tigltapileser III annaalid ja raidkirjad on üles ehitatud loogiliselt, need on enamasti hästi loetavad, kuid näiteks annaalil nr 15 on algus täiesti kadunud kiilkirjatahvel on saanud tugevasti kannatada (Tadmor 1994: 72-73). Read 1-2 on täiesti hävinud, kolmandast reast on säilinud vaid mõned märgid, neljanda ja viienda rea algused ning lõpud on kadunud jne.

Suurim probleem on muidugi see, et mõned tekstid või tekstiosad on säilinud fragmentaarselt, osa ridu on kaduma läinud ja nende tekstide rekonstrueerimine on tihtipeale suur väljakutse ning raske ülesanne.

\section{Sennaherib (704-681)}

Üks maailma ajaloo jõhkramaid valitsejaid oli Uus-Assüüria kuningas Sennaherib ehk Sanherib (Brinkman 1973: 89-95), kes tappis ja küüditas tuhandeid babüloonlasi, aramealasi, kaldealasi, juute, elamlasi ja muid rahvaid.

Babüloonia sõjakäiku kirjeldab Sennaherib ühes oma kroonikas väga detailselt, hoobeldes ja uhkustades oma vallutustega ja tuues küüniliselt ära täpse küüditatute ja tapetute arvu.

Read 9-10: Oma isanda Aššuri jõuga ma piirasin sisse Kaldu maa [Babüloonia] 89 võimsat linna [ja] kindlust ja 620 väikest maakohta [küla] nende ümbruses, vallutasin ja rüüstasin. Urbi, Aramu ja Kaldu inimesi Urukis, Nippuris, Kišis, Hursagkalammas, Kuthas [ja] Sipparis üheskoos linnakodanikega, kes ennast tabada ei lasknud, viisin ma minema ja arvestasin saagi hulka (TUAT 2005: 69; vt ka tõlget Sazonov 2010b: 162). 
Read 12-16: Tagasitulekul vallutasin ma ühtviisi Tu'muna, Rihihu, Jadaqqu, Hamrānu, Hagarān'i, Nabatu [ja] Li'tau, [minule] mitte truualamlikke aramea [hõime]. 208000 inimest, suuri [ja] väikeseid, mehi [ja] naisi, 7200 hobust [ja] muula, 11073 eeslit, 5230 kaamelit, 80100 härga [ja] 800600 lammast viisin ma raske saagina Aššuri maale. Oma sõjakäigu jooksul sain ma Nabū-bēl-sumāte'lt, Hararatu linna valitsejalt, nii kulda, hõbedat, suuri mooruspuuvilju, eesleid, kaameleid, härgi ja lambaid kui ka tema kaalukaid andameid. Hirimmu linna elanikke, kangekaelseid [põikpäiseid] vastaseid, surusin maha [lõin maha] relvadega, mitte ühtegi järele jätmata. Nende laibad riputasin ma postidele ning ümbritsesin nendega linna (TUAT 2005; vt ka tõlget Sazonov 2010b: 162).

Sennaheribi annaalid on tavaliselt üsna detailsed, pikad, kirjeldavad ta sõjakäike ja loetlevad vallutatud maid, linnu, küüditatud ja tapetuid inimesi jne. See pole sugugi uudne Assüüria annaalide ja raidkirjade jaoks. See oli juba üsna levinud Uus-Assüüria ajastu alguses ja kohati leidub seda juba ka Kesk-Assüüria kuningate raidkirjades (vt näiteks Tukultî-Ninurta I tekste nagu RIMA 1, A.0.78.23, lk 272, read 27-30; RIMA 1, A.0.78.24, lk 275, read 23-25).

Isegi brutaalsete assüürlaste seas peeti Sennaheribi liiga karmiks ja lõpuks ta tapeti - tema pojad organiseerisid vandenõu ja tapsid oma isa 681. a. eKr.

Kroonikate, annaalide ja raidkirjade koostamine jätkus Assüürias ka hiljem kuni 7. saj lõpuni, mil Assüüria impeerium hävis. 7. saj eKr paistsid silma veel sellised viimased suurkujud UusAssüüria kuningate seast nagu Assarhaddon (680-669) (RINAP 4; Parpola, Watanabe 1988; Wiseman 1958) ja ta poeg Aššurbanipal (669-627), kuid olulisi muudatusi või uusi elemente nad sisse ei viinud. Seega pole Sennaheribi ja Assarhaddoni kroonikate, raidkirjade ja annaalide vahel erinevusi. Nii oma stiili, struktuuri kui kompositsiooni poolest on need üpris sarnased. 


\section{Kokkuvõte}

Nagu näha, on $c a 1700$ a jooksul (alates ca 2300 kuni $612 \mathrm{eKr}$ ) Aššuris (hiljem Assüüria) toimunud tohutu areng kõikides valdkondades - nii riikluse kui riikliku ideoloogia arengus, kirjanduses ja ajaloolise sisuga tekstide koostamisel (raidkirjad, annaalid, kroonikad). Alustame kas või sellest, et annaale Assüürias 2000 a paiku eKr veel polnud, raidkirju hakati kirja panema ca 2300 2200 eKr Akkadi impeeriumi mõjutustel, mille ülemvõimu alla kuulus ka Aššuri linn. Kuid need raidkirjad olid veel väga lühikesed ja primitiivsed ning tagasihoidlikud. Kui II eelkristliku aastatuhande alguses olid Assüürias vaid väga lakoonilised ja üksikud valitseja-raidkirjad tagasihoidliku titulatuuriga, kus polnud peaaegu üldse sõjaliste kampaaniate kirjeldusi, siis II eelkristliku aastatuhande lõpuks tekivad juba pikemad ja mahukamad raidkirjad, keerulisema struktuuriga, mis meenutavad veelgi hilisemaid Uus-Assüüria ajastu väga põhjalikke ja detailseid annaale, kus on üksikasjalikult ära märgitud valitseja titulatuur, genealoogia, valitseja sõjaretkede ja kampaaniate kirjeldus ning teised tegevused. Areneb ka kroonikate kirjutamine. Selles osas avaldasid Assüüriale suurt mõju naaberrahvad ja -riigid nagu Hetiidi impeerium, kust saigi annaalide kirjutamine alguse, aga ka babüloonlased ja hurriidid.

Peale välismõjude on Assüüria raidkirjade, annaalide ja kroonikate teke ning areng Assüüria riikluse arenguga, samuti Assüüria võimsuse ja prestiiži kasvuga ajavahemikul 14-7 saj eKr. Alguse sai kõik sellest, kui väike linnriigike Aššur, mis ei mänginud II eelkristliku aastatuhande I poolel mingit erilist rolli Mesopotaamia poliitikas, muutus juba 13. eelkristliku sajandi keskpaigaks tugevaks impeeriumiks. Just siis tekkisidki imperialistlik mõtlemisviis, kuningate pretensioonid ning soovid kontrollida tervet Lähis-Ida ehk siis laiemas mõttes maailma. I eelkristliku aastatuhande alguseks muutub Assüüria impeerium veelgi võimsamaks. Ka kuningavõim on siis muutunud piiramatuks. Assüüria kuningavõimu tugevnemise ja eduka ekspansiooniga kaasnesid propagandistlike 
tekstide hulga kasv ning nende areng, mh arenesid ka raidkirjad, mis kajastasid valitsejate tegusid. Tekkis tugev valitseja isikukultus, mis kulmineerus Uus-Assüüria ajastul. Lisaks kõigele leiab aset universalistlike ning muude väga auahnete tiitlite ja epiteetide kasutuselevõtt, nagu "universumi kuningas", "nelja ilmakaare kuningas", "kõikide inimeste päikesejumal", "isandate isand", "kuningate kuningas", "vürstide vürst" jne. Kuningas on jumaluste lemmik ja väljavalitu, tihtipeale ka peapreester, riigi ülemkohtunik ja sõjaväe juht jms. Assüüria kuningate pantokraatlikud soovid on hästi väljendatud kuninglikes raidkirjades, annaalides ning nende fraseoloogias ning ka kuninglikes tiitlites ja epiteetides.

Vanade lakooniliste raidkirjade asemel tulid Kesk-Assüüria ajastu lõpuks ja eriti Uus-Assüüria ajastu alguseks mahukad, pikad, kohati keerulisema sõnastusega, ilutseva stiili, tihtipeale valitsejate valitsemisaastate järgi dateeritud tekstid (näiteks annaalid) või siis muud samalaadsed tekstid (kroonikad, raidkirjad), mille eesmärk oli jäädvustada sündmusi, mis toimusid selle valitseja valitsemisajal ning samuti ülistada valitseja isikut ning ta dünastiat. Raidkirjad on tendentslikud, äärmiselt propagandistlikud, vahel täis faktide ja arvude moonutamist, mõnikord lausa fiktsioone, kuid samas saab neid siiski pidada ajaloolisteks tekstideks, kuna need on tihtipeale ainsad allikad Lähis-Ida teatud ajalooperioodide kohta.

Vaadates läbi terve hulga Uus-Assüüria ajastu kuningate raidkirju ja annaale, võib jõuda järeldusele, et need on üpris sarnased nii oma kompositsiooni, struktuuri kui sõnastuse poolest, kuid siiski on mõned erinevused ja omapära olemas. Muidugi toimub areng ja ligi 250 aasta jooksul õpitakse Uus-Assüüria riigis koostama ametlikke raidkirju, kroonikaid ja annaale üpris osavalt. Propaganda meetmed arenevad ja muutuvad täiuslikumaks. Annaalide struktuur põhineb ajalisel järgnevusel: tekst koostatakse valitseja valitsemisaastate järgi, ka kroonikates on see üpris tavaline.

Probleeme on selliste tekstide tõlkimiesl palju. Kuidas õigesti tõlkida akkadi keelest eesti keelde? Kuidas tõlkida nii, et sisu oleks täpne, aga ka stiil oleks arhailine ning arusaadav ja mitte konaralik? 
Mõned konkreetsed probleemid on järgnevad:

1) Kiilkirjatekstide dešifreerimine ja tõlkimine võib olla üsna keeruline ülesanne, eriti, kui tekst on saanud kannatada ning osa kiilkirjamärke pole loetavad ja kui tekst on kirjutatud keerulises ilukirjanduslikus keeles.

2) Tõlkimise seisukohast on kindlasti vaja vältida sõna-sõnalist otsetõlget, mis eesti keeles võib kõlada väga konarlikult ning jäädaisegi arusaamatuks.

3) Raidkirjade ja annaalide tõlkimise puhul on peamiseks sama reegel, mis kehtib ka ilukirjandusliku sisuga tekstide tõlkimisel, ehk - tuleb kasutada nii originaalilähedast lausestruktuuri kui võimalik, samas peab sihttekst olema lugejaskonna jaoks hästi arusaadav. Muidugi tuleb mõelda ka sihtkeele stiili peale, kuna see on oluline, sest täpne, aga konarlik tõlge võib põhjustada raskusi lugemisel ja arusaamisel. Näiteks üks tõsine probleem tõlkimisel akkadi keeles eesti keelde on lauseehitus, kuna akkadi keel on semiidi keel, mis erineb tugevasti soome-ugri keeltest. Eesti keeles pole grammatilist sugu, akkadi keeles on jne.

4) Tähtis on silmas pidada, et eri liiki tekstid nõuavad ka erisuguseid tõlkemeetodeid.

\section{Lühendid}

AfO - Archiv für Orientforschung.

AOAT - Alter Orient und Altes Testament, Veröffentlichungen zur Kultur und Geschichte des Alten Orients und des Alten Testaments. Kevelaer/Neukirchen-Vluyn, $1969 \mathrm{ff}$.

JCS - Journal of Cuneiform Studies.

JAOS - Journal of the American Oriental Society 


\section{Allikad}

al-Rawi, Farouk N. H. 2008. Inscriptions from the Tombs of the Queens of Assyria. - New Light on Nimrud.Proceedings of the Nimrud Conference $11^{\text {th }}-13^{\text {th }}$ March 2002. Eds. J. E.Curtis, H. McCall, D. Collon, L. al-Gailani Werr. London: British Institute for Study of Iraq in association with the British Museum, pp. 119-138.

Black, J. A., Cunningham, G., Ebeling, J., Flückiger-Hawker, E., Robson, E., Taylor, J., and Zólyomi, G. 1998 - The Electronic Text Corpus of Sumerian Literature (http://etcsl.orinst.ox.ac.uk/). Oxford.

Foster, B. R. 2005. Before the Muses. An Anthology of Akkadian Literature. Third Edition. Bethesda, Maryland: CDL Press.

Glassner, J.-J. 2004. Mesopotamian Chronicles. - Writings from the Ancient World. Atlanta: Society of Biblical Literature.

Grayson. A. K. 1975. Assyrian and Babylonian Chronicles.- Texts from Cuneiform Sources, Volume V. Eds. A. L. Oppenhein, M. Civil, E. Reiner, E. Sollberger. Locust Valley, New York: J.J. Augustin Publisher.

Grayson, A. K. 1976. Assyrian Royal Inscriptions, Volume II, Part 2, From Tiglath-pileser I to Ashur-nasir-apli II, Records of The Ancient Near East. Ed. H. Goedicke. Wiesbaden: Harrassowitz.

RIMA 1 = Grayson, A. K. 2002. Assyrian Rulers of the Third and Second Millennia BC (to $1115 \mathrm{BC}$ ). - The Royal Inscriptions of Mesopotamia, Assyrian Periods, Volume 1. Toronto, Buffalo, London: University of Toronto Press.

RIMA 3 = Grayson, A. K. 1996. Assyrian Rulers of the Early Fisrt Millennium BC II (858-745 BC). - The Royal Inscriptions of Mesopotamia, Assyrian Periods, Volume 3. Toronto, Buffalo, London: University of Toronto Press.

RINAP 4 = Leichty, E. 2011. The Royal Inscriptions of Esarhaddon, King of Assyria (680-669). - The Royal Inscriptions of the Neo-Assyrian Period, Volume 4. Winona Lake, Indiana: Eisenbrauns.

ITN = Weidner, E. 1970. Die Inschriften Tukulti-Ninurtas I. und seiner Nachfolger, Archiv für Orientforschung, Beiheft 12. Hrsg. E.Weidner. Osnabrück: Biblio Verlag.

Machinist, P.B. 1978. The Epic of Tukulti-Ninurta I. A Study in Middle Assyrian Literature. A Dissertation Presented to the Faculty of the Graduate School of Yale University in Candidacy for the Degree of Doctor of Philosophy. Käsikiri. 
Parpola S., Watanabe, K. 1988. Neo-Assyrian Treaties and Loyalty Oath. - State Archives of Assyria, Volume 2. Helsinki: Helsinki University Press.

Rasmussen, N. 1897. Salmanasser den II's Indskrifter, Kileskrift, Transliteration og Translation, samt Commentar til Monolith-Inskriften. Col. 1. Kjøbenhavn: I Komssion hos Boghandler Kayser, Nielsen \& Lydiches Bogtrykkeri.

Stein, P. 2000. Die mittel- und neubabylonischen Königsinschriften bis zum Ende der Assyrerherrschaft, Grammatische Untersuchungen. - Jenaer Beiträge zum Vorderen Orient 3. Wiesbaden: Harrassowitz Verlag.

Tadmor, H. 1994. The Inscriptions of Tiglath-pileser III King of Assyria, Critical Edition, with Illustrations, Translations and Commentary. Jerusalem: The Israel Academy of Sciences and Humanities.

TUAT 2005 = Texte aus der Umwelt des Alten Testaments 2005. Neue Folge, Band 2, Staatsvertäge, Herrscherinschriften und andere Dokumente zur politischen Geschichte. Hrsg. B. Jankowski, G. Wilhelm. Gütersloh: Güterslohwer Vergshaus.

Wiseman, D. J. 1958. The Vassal-Treaties of Esarhaddon, Iraq XX, Part I. London: The British School of Archaeology in Iraq.

\section{Kirjandus}

Aboud J. 1994. Die Rolle des Königs und seiner Familie nach den Texten von Ugarit. - Forschungen zur Anthropologie und Religionsgeschichte, Band 27. Münster: Ugarit-Verlag.

Artzi, P. 1978. The Rise of the Middle-Assyrian Kingdom according to El-Amarna Letters 15\&16. A Contribution to the Diplomatic History of Ancient Near East in the mid-second Millenium B.C.E. - Bar-Ilan Studies in History. Ed. P. Artzi. Ramat-Gan: Bar-Ilan University Press, pp. 25-41.

Brinkman, J. A. 1973. Sennacherib’s Babylonian problem: an interpretation. JCS no 25, pp. 89-95.

Brinkman, J. A. 1997. Unfolding the Drama of Assyrian Empire. - Assyria 1995, Proceedings of the 10th Anniversary Symposium of the Neo-Assyrian Text Corpus Project, Helsinki, September 7-11, 1995. Eds. S. Parpola, R. M. Whiting. Helsinki: The Neo-Assyrian Text Corpus Project, pp. 1-16. 
Borger, R. 1961. Einleitung in die assyrischen Königsinschriften. Teil 1, Das zweite Jahrtausend v. Chr. Leiden, Köln: Brill.

Bunnes, G. 1997. Til Barsib under Assyrien Domination: A Brief Account of the Melbourne University Excavations at Tell Ahmar. - Assyria 1995, Proceedings of the 10th Anniversary Symposium of the Neo-Assyrian Text Corpus Project, Helsinki, September 7-11, 1995. Eds. S. Parpola, R. M. Whiting. Helsinki: The Neo-Assyrian Text Corpus Project, lk 17-28.

Cancik-Kirschbaum, E. 2003. Die Assyrer: Geschichte, Gesellschaft, Kultur. München: Verlag C. H. Beck.

del Monte, G.F. 1993. L'annalistica ittita. - Testi del Vicino Oriente antico 4. Letterature dell'Asia Minore a cura di Fiorella Imparati. Brescia: Paideia Editrice.

Faist, B. 2001, Der Fernhandel des assyrischen Reiches zwischen dem 14. und 11. Jh. v.Chr. - AOAT 265, Veröffentlichungen zur Kultur und Geschichte des Alten Orients und des Alten Testaments. Hrsg. M. Dietrich, O. Loretz. Münster: Ugarit-Verlag.

Foster, B.R. 2007. Akkadian Literature of the Late Period. Münster: Ugarit-Verlag.

Harrak, A. 1987. Assyria and Hanigalbat. A Historical Reconstruction of Bilateral Relations from the Middle of the Fourteenth to the End of the Twelfth Centuries B.C. Texte und Studien zur Orientalistik, Band 4. Hildesheim, Zürich, New York: Georg Olms Verlag.

Heinhold-Krahmer, S. 1988. Zur Salmanassars I. Eroberungen im Hurritergebiet. - AfO 35, pp. 79-104.

Holloway S.W. 2002. Aššur is King! Aššur is King! Religion in the Exercise of Power in the Neo-Assyrian Empire. - Eds. B. Halpern, M. H. E. Weippert, Th. Ph. J. Van den Hout, I. Winter, Volume 10. Leiden, Boston, Köln: Brill.

Jankovskaja 1968 = Янковская, Н. Б. Клинописные тексты из Кюль-тепе из собрания СССР (письма и документы торгового объединения в Малой Азии XIX в. до н.э.). Автографические копии, транскрипция перевода, вводная статья, комментарий и глоссарий Н. Б. Янковской. - Памятники Письменности Востока XIV. Москва: Издательство Наука 1968.

Klengel, H. 1961. Tukulti-Ninurta I, König von Assyrien. - Das Altertum 7, pp. 67-77.

Lambert, W. G. 1974. The Reign of Aššurnasirpal II and Shalmaneser III: An Interpretation. - Iraq 36, pp. 103-109. 
Lambert,W. G 1976. Tukultī-Ninurta I and the Assyrian King List. - Iraq 38, pp. 85-94.

Lambert, W. G. 2004. The Enigma of Tukultī-Ninurta I. - Studies on the History of Assyria and Babylonia in Honor of A. K. Grayson. Toim. G. Frame, L.Wilding. Nederlands Instituut Voor Het Nabije Oosten, pp. 197-202.

Liverani, M. et al. 1992. Studies on the Annals of Ařšurbanipal II, Volume II. Topographical Analysis. La Sapienza: Universita di Roma.

Mayer, W. 1995. Politik und Kriegskunst der Assyrer. - Abhandlungen zur Literatur Alt-Syrien-Palästinas und Mesopotamiens. Band 9. Hrsg. M. Dietrich, O. Loretz. Münster: Ugarit-Verlag.

Müller, K. Fr. 1937, Das Assyrische Ritual, Teil I. Texte zum assyrischen Königsritual. - Mitteilungen der Vorderasiatisch-Aegyptischen Gesellschaft (E.V.), 41. Band, 3. Heft, Lepzig: J.C. Hinrichs Verlag.

Nemirovski 2008 = Немировский, А. А. 2008. К истории хетто-ассирийских отношений в конце XIII - начале XII в. до н.э - Вестний Древней Истории 2, с. 3-24.

Oded, B. 1979. Mass Deportations and Deportees in the Neo-Assyrien Empire. Wiesbaden: Dr. Ludwig Reichert Verlag.

Olmstead, A.T. 1917. Tiglath-Pileser I and his wars. - JAOS 37, pp. 169-185.

Röllig W. 1967. Die Glaubwürdigkeit der Chronik P. - Heidelberger Studien zum Alten Orient. Wiesbaden: Otto Harrassowitz, pp. 173-184.

Sazonov, V. 2006. Arad-Ahhešu kiri Aššurbanipalile. - Tuna 1, lk 80-87.

Sazonov, V. 2010a. Die Königstitel und -epitheta in Assyrien, im Hethiterreich und in Nordsyrien (Ugarit, Emar, Karkemiš) in der mittelassyrischen Zeit: Strukturelle Gemeinsamkeiten, Unterschiede und gegenseitige Beeinflussung. Dissertationes Historiae Universitas Tartuensis 21. Tartu: Tartu Ülikooli Kirjastus.

Sazonov, V. 2010b. Küüditamispoliitika kui muistne tava Uus-Assüüria impeeriumis 9.- 7. sajandini eKr. - Mäetagused 44, lk 153-174.

Sazonov, V. 2011. Die mittelassyrischen, universalistischen Königstitel und Epitheta Tukulti-Ninurtas I (1242-1206). - Identities and Societies in the Ancient East-Mediterranean Regions: Comparative Approaches, Henning Graf Reventlow Memorial volume. Acta Mediterranea et Oreintalia, Band 1, Alter Orient und Altes Testament Band 390/1. Hrsg. Th. R. Kämmerer. Münster: Ugarit-Verlag, pp. 235-276. 
Solovjova, Nemirovski 2007 = С. С. Соловьева, А. А. Немировский, Глава 11. Месопотамия во II тысячелетии до н.э. Преобладание Вавилона. - История Древнего Востока, издание третье, переработанное и дополненное. Ред. В. И. Кузищин. Москва: Высшая школа 2007, с. 128-143.

Veenhof, K. R. 1972. Aspects of Old Assyrian Trade and Its Terminology. Leiden: Brill.

Weidner, E. 1939-1941. Studien zur Zeitgeschichte Tukultī-Ninurtas I. - AfO13, pp. 109-124.

Yamada, Sh. 2000. The Construction of the Assyrian Empire. A Historical Study of the Inscriptions of Shalmaneser III (859-824 BC) relating to His Campaigns to the West. Culture and History of the Ancient Near East, volume 3. Eds. B. Halpern, M. H. E. Weippert, Th. P. J. van den Hout, I. Winter. Leiden, Boston, Köln: Brill.

\section{Summary}

\section{Some Comparative Remarks Concerning Middle- and Neo-Assyrian Royal Inscriptions, Chronicles and Annals (ca 1500-612 BCE) and Problems Related to Translation of This Kind of Texts}

The current article is dedicated to the analysis of some Middleand Neo-Assyrian chronicles, annals and royal inscriptions and some aspects and problems related to the translation of such texts. This overview gives also a short introduction into Assyrian history from its beginning until the end of Neo-Assyrian Empire in 612 BCE and into "historical" or "pseudo-historical" texts (royal inscriptions, chronicles etc.) and their development during the II millennium BCE and the first half of the I millennium BCE. The author concentrates on some aspects of Babylonian, Hittite and other influences on Assyrian writing in the form of chronicles, inscriptions and annals. Some questions of royal propaganda are 
also addressed, such as textual representation of royal titles, military conflicts, deportation of people, looting of cities, etc.

The second part of the article focuses on some important and difficult problems a translator faces when translating such texts, such as deciphering and interpretation of cuneiform texts (texts may be razed, have lacunas, they are often too fragmentary, problems arise with understanding terms, some difficult grammatical forms, etc.).

Key words: Assyria, chronicles, inscriptions, annales, ideology, kings, propaganda, translation problems 